\title{
Seleção por competência: Ficção ou possibilidade?
}

\author{
Selection by competences: Possibility or fiction?
}

\author{
Francinaldo do Monte Pinto ${ }^{[a]}$, Gabrielle Bezerra Gomes ${ }^{[b]}$
}

\footnotetext{
${ }^{[a]}$ Doutor em Psicologia Social pela Universidade do Estado do Rio de Janeiro (UERJ), professor de Psicologia do Trabalho do Centro Universitário de João Pessoa (Unipe) e da Universidade Estadual da Paraíba (UEPB), João Pessoa, PB - Brasil, e-mail: dumontepinto@uol.com.br

${ }^{[b]}$ Graduada em Psicologia pelo Centro Universitário de João Pessoa (Unipe), Psicóloga do Trabalho da Construtora Hema Ltda, João Pessoa, PB - Brasil, e-mail: gabybgomes@hotmail.com
}

Recebido: 18/09/2010 Received: 09/18/2010

Aprovado: 10/03/2011 Approved: 03/10/2011

\section{Resumo}

Este estudo, de natureza bibliográfica, analisa o processo de seleção por competências, amplamente difundido como nova modalidade de gestão de pessoas nas organizações de trabalho. Busca-se conhecer as técnicas utilizadas nesse tipo de seleção, que começa pelo recrutamento/ atração de pessoas, com o intuito de expor o seu diferencial em relação aos processos seletivos tradicionais. Observa-se que a necessidade de acompanhar as mudanças ocorridas no mundo do trabalho acarreta inúmeras exigências - agilidade, inovação, criatividade, efetividade de resultados - aos trabalhadores e ao modo de selecioná-los. Na revisão de literatura, que trata do tema da seleção por competência, não foram encontrados resultados significativos em termos de inovação ou mudança em relação ao modelo tradicional de selecionar pessoas. Verificamos duas concepções de modelos de competências que versam sobre este tema. De um lado, encontra-se um grupo vinculado à área de gestão de pessoas, que defende/m o modelo de seleção por competências a partir do antigo trinômio, outrora utilizado na clássica administração de recursos humanos (ARH), de avaliação de conhecimentos, habilidades e atitudes (CHA), como requisitos fundamentais que credenciam um profissional a exercer uma determinada função ou cargo. De outro, uma corrente de pensadores que caracteriza/m a competência como um retorno do trabalho ao trabalhador. Nessa segunda concepção, destacam-se os conceitos de entrega, responsabilidade, iniciativa e autonomia. Conclui-se, portanto, não haver um modelo geral para esse "novo" tipo de seleção, embora se apresente uma perspectiva de mapeamento de competências que considera interesses do trabalhador à missão estratégica da organização.

Palavras-chave: Seleção. Atração. Modelo de competências.

\begin{abstract}
This bibliographic study, analyzes the selection process by competences, widely defined as a new model for people management in working organizations. It seeks to know the techniques used in this type of selection, which begins with the recruitment/attraction of people, with the aim to expose its differential compared to the techniques of traditional selection process. It is observed that the need to monitor the changes in the world of work entails many requirements - flexibility, innovation, creativity, effectiveness of results - to the employees and how to select them. In the review of literature dealing with the issue of selection by competences, significant results were not found in terms of innovation or change from the traditional model of selecting people. We found two conceptions of competence models which deal with this issue. On one hand, there is a group with ties to the area of people management, that defends the selection model by competences based on the old
\end{abstract}


triad, once used in the classic people management (PM) - assessment of knowledge, skills and attitudes (KSA) - as basic requirements that qualify a professional to perform a particular function or position. On the other hand, there is a stream of scholars that characterize competence as a return of the work to the worker. Through this second conception the concepts of delivery, responsibility, initiative and autonomy stand out. The conclusion, thus, is that there is not a general model for this "new" type of selection, although it presents a perspective of competence mapping that considers interests of the employees under the strategic mission of the organization.

Keywords: Selection. Attraction. Competences model.

\section{Introdução}

A seleção com foco em competência é uma ferramenta bastante discutida, atualmente, no contexto do trabalho, o qual busca continuamente novos meios para o seu próprio benefício. Assim, o presente trabalho consistiu em abordar este tema, tendo por objetivos principais da pesquisa, analisar o processo de seleção de pessoas, como também expor o seu diferencial em relação aos processos de seleções tradicionais.

Sabe-se que o trabalho sempre esteve presente na história da humanidade, sendo seu objetivo inicial, a sobrevivência. Segundo Malvezzi (2004), o trabalho é uma ação que transforma a realidade e tem como objetivo a satisfação das necessidades humanas. Com ele, além de transformar a natureza, o homem transforma a si mesmo e, dessa forma, todo o seu significado depende do contexto em que a pessoa se encontra.

Com o passar dos anos, o mundo do trabalho foi profundamente influenciado e transformado pelo desenvolvimento de novas tecnologias e importantes mudanças na economia internacional, entre outros fatores. Modifica, assim, não só os meios de trabalhar, mas suas relações de trabalho, exigindo dos profissionais, mais agilidade, inovação, criatividade e efetividade de resultados. Tais fatos expuseram o esgotamento do modelo taylorista/fordista, que predominou na produção até a década de 1970, dando lugar aos novos modelos de gestão e suas novas técnicas de recrutamento e seleção.

Apesar de o recrutamento e seleção terem se constituído como técnica, somente a partir do século XX o curso de sua evolução se entrelaça com a história do trabalho, variando conforme as transformações econômicas, na perspectiva do tipo de profissional requerido. E, a partir das rápidas mudanças decorrentes do avanço tecnológico e do processo de globalização, foi se reforçando a necessidade de se redefinir um novo perfil profissional, adaptado à realidade do trabalho nas organizações, e fazendo emergir outras exigências, qualificações e competências ao então chamado processo seletivo.

O movimento de mudanças e transformações no mundo do trabalho (globalização, aumento da competitividade, necessidade da utilização de técnicas avançadas de negociação), culminou em um redimensionamento no modo de trabalhar, especialmente quanto à necessidade do trabalho em equipe, com acentuada valorização ao tema das competências.

Nesse cenário, alguns autores (Davel \& Vergara, 2001; Gramigna, 2007) afirmam que esse processo de seleção por competências é de grande importância e está, cada vez mais, ganhando espaço nas organizações. Isso porque, por meio de suas ferramentas, diminui as chances da seleção não ser bem sucedida, estando munida da capacidade de medir cada habilidade que os indivíduos possuem, para um bom desempenho no cargo.

Para tanto, desenvolveu-se uma pesquisa descritivo-exploratória, de cunho bibliográfico, na qual foi feita uma análise qualitativa, visando a preservar a fidedignidade em relação à problemática e objetivo da pesquisa. Especificamente, o presente trabalho fornece um panorama sobre a emergência desse modelo, assim como assinala os ideários de recrutamento e seleção adotados pelas organizações. Além disso, buscou-se ainda problematizar diferentes concepções de seleção de pessoas mais utilizados pelos profissionais da atualidade, como principal estratégia de seleção por competência. 


\section{Recrutamento/atração e seleção de pessoas}

A prática do recrutar

O recrutamento de pessoas é uma prática que ocorre há séculos, ao longo de toda a história da humanidade. Essa expressão teve sua procedência advinda da palavra recrutar, na qual sua morfologia e significado foram reconhecidos, isso praticamente no sistema militar.

A primeira utilização desse termo, no Brasil, data dos primórdios de 1574, quando a "Provisão sobre as Ordenanças" assinalou o início da regulamentação sobre a prestação do serviço militar, na qual todo o cidadão, entre 14 e 60 anos, era obrigado a servir nas Companhias de Ordenanças (Ministério da Defesa, 2006).

No Império, já existia e depois, após a Independência, foi reafirmada a obrigatoriedade do serviço militar na Constituição de 1824, na qual o artigo 145 estabelecia que todos os brasileiros são obrigados a pegar em armas para sustentar a independência, a integridade do Império e defendê-lo de seus inimigos. 0 recrutamento, nessa época, era realizado por patrulhas, que percorriam as tabernas durante a noite, prendendo todos os homens; entre eles, as autoridades escolhiam os que deveriam assentar praça (Ministério da Defesa, 2006).

Logo, foram percebidas deficiências na área de pessoal, observadas durante a Guerra do Paraguai (também chamada Guerra da Tríplice Aliança), na qual o Império brasileiro instituiu uma nova modalidade de recrutamento - o sorteio militar -, para complementar o alistamento voluntário, que já era destinado ao Exército e à Marinha.

Diante desse contexto, foi sancionada a Lei n. 2556, de 26 de setembro de 1874, que adotou o sorteio para o serviço militar. Nessa lei, o artigo primeiro atribuía que o recrutamento para o Exército e a Armada seria feito por engajamento e reengajamento voluntários e, na deficiência de voluntários, por sorteio dos cidadãos brasileiros alistados anualmente, em conformidade com esse dispositivo legal (Ministério da Defesa, 2006).

Nota-se que a palavra recrutar está vinculada à prática de captar recrutas para vagas de futuros soldados ou postos de guerrilha. Assim, conforme o exposto no dicionário Aurélio, no século XXI, a palavra recrutar significa "arrolar para o serviço militar" (Ferreira, 2004).
Posteriormente, com o advento da Revolução Industrial e o início do capitalismo, o sistema industrial introduziu esse termo para a captação de seus futuros funcionários, como o primeiro passo na procura de pessoal. Dessa nova ordem, decorreu a necessidade de se pensar a sistematização de mecanismos que possibilitassem promover maior eficiência e produtividade, em face da crescente concorrência e competição no mercado. Nesse período, o recrutamento de operários para nova economia se realizou, sobretudo, por meio de formas coercitivas.

Nessa época, percebe-se que a necessidade das organizações analisarem os candidatos e futuros profissionais, durante o processo de recrutamento, partiu de uma perspectiva mais ampla de suas principais características. Valorizavam-se, além das condições físicas, a capacidade de eles se submeterem às regras empresariais, sem oferecer maiores resistências, e de possuírem o domínio completo dos aspectos operacionais de seus ofícios.

Nos tempos atuais, essa técnica varia de acordo com as políticas dos recursos humanos adotadas pelas empresas. Sem essa etapa, a contratação de funcionários não ocorre, pois a seleção está completamente encadeada nesse processo e, por meio desse seguimento, a empresa selecionará candidatos com os requisitos necessários para o exercício de um cargo. 0 recrutamento dá subsídios para o processo de seleção. Se não existirem candidatos com potencial para o preenchimento de uma vaga, não haverá como efetuar a seleção (Limongi-França \& Arrelano, 2002 citado por Soares, 2007).

Com a modernização dos processos tecnológicos e organizacionais, o termo recrutamento apresentou outras definições, as quais a maioria dos autores considera ser o meio de encontrar e atrair candidatos para posições abertas na organização, recebendo denominações como captação, atração, entre outros (Chiavenato, 1999; Oliveira, 2008; Santos, 1985).

\section{0 modo de selecionar pessoas}

Foi no cenário da consolidada Revolução Industrial que a seleção de pessoal começou a ingressar no mundo do trabalho. Essa nova era nasceu no Taylorismo, ideologia da escola clássica de administração, que visa, por meio de técnicas de maior controle sobre o trabalho e da produção em massa, ao aumento da produção. 
Nessa fase de surgimento, notadamente nos anos 1930, a Psicologia Industrial, baseada nos fundamentos das diferenças individuais, do funcionalismo e do behaviorismo, emerge junto aos interesses dos industriais e do desenvolvimento da economia, sobretudo voltada ao estudo da produtividade em função do esforço. De acordo com Sampaio (1998), a prática da chamada Psicologia Industrial limitou-se inicialmente à seleção e colocação do profissional, orientação vocacional (baseada em testes) e estudos sobre as condições de trabalho e treinamento, com o objetivo de elevar a produtividade. Esse autor informa ainda que o primeiro livro da área, Psychology and Industrial Efficiency, escrito por Hugo Münsterberg, em 1912, estuda a produtividade em função do esforço. Naquela época, somente a psicologia aplicada ao trabalho, a psicotécnica (avaliação psicológica que se realiza, de modo geral, nas indústrias e organizações) estudava as funções mentais sob o ponto de vista das medidas, bem aderente ao pensamento clássico em administração.

A partir desses primeiros trabalhos, a difusão da psicotécnica, com fins de seleção, foi enorme. No ano de 1917, os trabalhos se estenderam, com aplicações de testes em 1.700.000 recrutas no exército americano, surgindo, logo após, as primeiras instituições destinadas à orientação e à seleção profissional, das quais destacaram-se o Gabinete de Orientação Profissional do Instituto Jean Jacques Rousseau, em Genebra, no ano de 1916; o Laboratório de Psicologia Industrial, de Charlottenbourg, em 1918; o Gabinete de Psicologia do Trabalho, em Módena, 1920; o Instituto de Orientação Profissional, em Barcelona, 1919; o Instituto do Trabalho, em Moscou, 1920; o Instituto Nacional de Psicologia Industrial de Cambridge, em 1920, e outros mais (Santos, 1985).

Sabe-se que, durante longo período, a psicotécnica foi considerada uma das principais responsáveis por conferir status científico às praticas de seleção (Carvalho, Passos \& Saraiva, 2008). Todavia possuiu uma finalidade social, especialmente na França na época da Primeira Guerra Mundial, na qual buscava compreender o que se denominava "aptidões" dos trabalhadores no auge do fortalecimento industrial, atualmente consideradas competências (Clot, 2010).

Durante o movimento taylorista/fordista, até um tempo atrás, a contratação de um profissional de qualquer área era feita observando-se apenas sua experiência profissional, sob o aspecto técnico, para ocupar um determinado cargo ou função solicitada (aberta) pelas empresas. Nos dias atuais, a prática sofreu muitas alterações. Os departamentos de áreas de recursos humanos (hoje, denominados "Gestão de Pessoas") mudaram consideravelmente a forma de selecionar pessoas. Os selecionadores de empresas, ou mesmo de agências de emprego, buscam também selecionar profissionais qualificados tecnicamente.

Mas isso não basta para atender às expectativas das empresas/mercado. Faz-se necessário, ainda, que esse domínio técnico venha acompanhado de uma tipologia de comportamentos e atitudes compatíveis com a cultura, missão, visão e objetivos almejados pelas empresas.

Ressaltamos que o processo de seleção constitui uma série de passos específicos para decidir quais pessoas recrutadas devem participar do processo seletivo. Antes disso, convém apresentar alguns conceitos, largamente difundidos pelos teóricos da administração de recursos humanos ou "gestão de pessoas", acerca do que vem a ser seleção de pessoal, ou de pessoas.

A seleção de pessoal, conceituada como um conjunto de técnicas e procedimentos, visa a escolher e/ou classificar candidatos que melhor se enquadrem e garantam eficiência e eficácia ao cargo oferecido, conforme assevera Ribeiro (2009).

Na concepção de Santos (1985), a seleção é um processo pelo qual são escolhidas pessoas adaptadas a uma determinada ocupação, ou esquema operacional, ou seja, é a partir dela que se efetua a escolha dos melhores, daqueles que mais convém a um determinado plano de ação.

Já para Marras (2000), a seleção de pessoal tem por finalidade escolher, sob metodologia específica, candidatos a emprego recebido pelo setor de recrutamento, para o atendimento das necessidades internas da empresa.

Para Andrade (2009), autores, como Ribeiro e Biscoli (2004), consideram que a seleção de pessoal se dá por meio da comparação e escolha (decisão), e deve, necessariamente, advir de algum tipo de critério ou padrão, para alcançar a sua validade. E tal padrão tem como ponto de partida as características do cargo a ser preenchido.

Enfim, a seleção de pessoas funciona como uma espécie de filtro, que permite que apenas algumas pessoas possam ingressar na organização; aquelas que apresentam as características desejadas pela organização. Busca, dentre vários candidatos 
recrutados, aqueles que são mais "adequados" aos cargos existentes na empresa, "visando a manter ou aumentar a eficiência e desempenho do pessoal, bem como a eficiência da organização". (Chiavenato, 1999, p. 107). Assim, tem-se em vista, como objetivo imediato, o bem-estar, a produtividade, a eficiência de certo órgão ou entidade. 0 indivíduo é considerado apenas naquilo que interessa a esse grupo ou entidade.

Em suma: a seleção deve visar ao desenvolvimento das pessoas, e não meramente um processo de classificação e exclusão dos participantes, em função de conhecimentos, habilidades e competências exigidas à realização do trabalho.

\section{0 modelo de competência}

Segundo Ribeiro (2009), antes do século XX, o bom trabalhador era aquele que detinha uma habilidade profissional, o que configurava a qualificação como um atributo do indivíduo (intrínseca a ele), e advinda da experiência de trabalho na atividade ocupacional. Com o apogeu da consolidação do Taylorismo, no início do século XX, o "bom" trabalhador devia possuir os requisitos de eficácia e eficiência para o pronto desempenho da tarefa, sendo a qualificação vinculada aos processos de trabalho e advinda da aprendizagem formal realizada nos contextos educacionais, codificando e generalizando os requisitos da tarefa e a remuneração correspondente, e constituindo parâmetros claros para o desempenho e a remuneração (Ribeiro, 2009, p. 56).

Com o passar dos anos, a suposta objetividade (rigidez) dos processos organizativos tradicionais (encenada no taylorismo/fordismo) foi cedendo gradativamente o seu lugar, passando a uma subjetividade flexível (pós-fordismo/toyotismo). Acredita-se, então, que o atual contexto organizacional demanda alterações no processo de qualificação, bem como em seu próprio entendimento. Esse novo contexto transformou o conceito de qualificação (nascido e consolidado com o modelo taylorista-fordista de produção). Exigiu-se do trabalhador, a partir do modo de produção flexível, um tipo de conhecimento não restrito apenas ao técnico-operacional. A qualificação passou, assim, a depender menos de um saber-fazer técnico e mais da atitude, da comunicação e de traços de personalidade do trabalhador (Helal \& Rocha, 2008).
Observa-se, portanto, que nessa nova forma de organização do trabalho, passam a ser exigidos outros requisitos (até então pouco demandados), sobretudo no que concerne à maturidade adaptativa, e competências para o desempenho de suas tarefas.

Para alguns autores, como Zarifian (2003), Tomasi (2004) e Ribeiro (2009), essa nova forma de entendimento de qualificação é denominada competência. $\mathrm{O}$ foco do deslizamento conceitual ocorreu em face da mudança ("mutação") de conteúdos das atividades, ou seja, pela impossibilidade de codificação dos postos de trabalho.

Nesse sentido, percebe-se que muitos dos documentos produzidos sobre a questão por sociólogos franceses, no fim dos anos 1980 e início dos anos 1990, tinham como título Da qualificação às competências. Eles davam a ideia da passagem de uma noção a outra. E apontavam, evidentemente, não sem questionar a mudança, para a possibilidade de uma evolução no campo conceitual, ou seja, a substituição de uma noção pela outra. Aliás, a ideia de substituição estava expressa nas questões que introduziam os documentos. Após vários anos de debates, quando algum conhecimento parece já firmado, talvez o mais indicado seja falarmos em um rearranjo dessas noções, muito mais do que de substituição ou de superação de uma por outra (Tomasi, 2004).

Nesse sentido, Zarifian (2003) afirma que não devemos fazer nenhuma distinção conceitual entre competência e qualificação, a não ser para dizer que o modelo de competência especifica, hoje, de maneira nova, a construção da qualificação.

A qualificação é uma construção social cujo objeto é qualificar os indivíduos assalariados, tanto do ponto de vista do modo de apreciação da relação, mantida do que se espera deles (seu "trabalho"), quanto do ponto de vista da hierarquia na escala dos estatutos sociais e dos salários. A competência é uma nova forma de qualificação, ainda emergente. É uma maneira de qualificar (Zarifian, 2003, p. 37).

Seguindo o mesmo pensamento de Zarifian, Roche (2004) aponta que o fim da qualificação e a supremacia da competência é um mito construído ideologicamente, pois dá margem à ideia de que a experiência de vida, trabalho e de talentos individuais são mais importantes e até determinantes, para as possibilidades de inserção, manutenção e sucesso no trabalho e seriam independentemente da qualificação, o que não é verdade, visto que se trata de um discurso ideologicamente produzido. 
Assim, o que há de novo é o modo como cada conceito se posiciona no quadro organizacional. A noção de competência, segundo Helal e Rocha (2008), passa a complementar o conceito de qualificação, na medida em que as formas flexíveis e participativas de organização de trabalho, na atualidade, exigem conhecimentos específicos e direcionados (qualificação), bem como capacidade de lidar com as rápidas mudanças no decorrer do processo de trabalho, que necessitariam de elementos subjetivos e personalíssimos, como iniciativa, criatividade ou capacidade de assumir riscos (competência).

Completam ainda a nova proposta, afirmando que a maior diferença entre a noção de competência e qualificação não se dá no contexto técnico. A noção de competência traz à luz a necessidade de ligar o saber formal à prática, enquanto a qualificação se relaciona intimamente com os saberes técnicos adquiridos.

Nesse contexto, Ribeiro (2009) ressalta que a emergência desse "paradigma" das competências surgiu rapidamente em função de uma demanda por padrões mais flexíveis no mundo do trabalho, e foram logo utilizadas sem grandes discussões ou reflexões a esse respeito.

De outro ponto de vista, Zarifian (2003) afirma que a emergência da competência é uma transformação de longo prazo, que inaugura um novo período histórico. Ressalta, contudo, que o grande desafio da competência consiste na volta do trabalho para o trabalhador.

Mas afinal, qual têm sido a definição, o debate, as controvérsias sobre a noção de competência na atualidade? Sabe-se que o conceito de competência não é algo novo, mas ainda gera muita confusão, principalmente entre teóricos e pessoas que trabalham nessa temática. Encontram-se grandes e distintas discussões entre esses estudiosos para explicar a competência e também se nota ser comum encontrar pleonasmos nas explicações daqueles que trabalham com o assunto.

Nesse sentido, Ribeiro (2009) afirma que o trinômio CHA, composto por conhecimento (saber), habilidades (fazer) e atitudes (ser), consolidou-se como um parâmetro estável e, quase consensual, de análise dos requisitos necessários para um desempenho eficiente e eficaz nos processos de trabalho. Juntando as partes, a competência é largamente definida na literatura como um conjunto de conhecimentos, habilidades e atitudes necessários à realização de uma determinada tarefa e o alcance de um resultado preestabelecido.

Entretanto esse mesmo autor afirma que, com as mudanças operadas nos processos sociais e de trabalho, essa unanimidade (CHA) se desfaz e se fragmenta, fazendo surgir as competências como critérios definidores desse desempenho eficiente e eficaz, para além da limitada fórmula.

Para ele, a pessoa competente não tem apenas saberes e fazeres (qualificação) necessários ao desempenho do trabalho, mas deve adquirir, principalmente, a competência de não só mobilizar esses fatores, mas, acima de tudo, adaptá-los a cada nova situação que surge no cotidiano do trabalho.

Aqui, Zarifian $(2001,2003)$ trabalha a definição de competência, a partir da análise da questão da responsabilidade, no sentido de "responsabilidade por", que significa "ir até o fim de sua tomada de iniciativa", ou seja, "assumir a plenitude de sua ação", em termos de responder "por seu alcance, seus efeitos e suas consequências".

Assim, o autor propõe três definições para o termo:

1) Competência é a tomada de iniciativa e responsabilidade do indivíduo, em situações profissionais, com as quais se defronta.

2) Competência é uma inteligência prática das situações, que se apoia em conhecimentos adquiridos e os transforma, à medida que a diversidade das situações aumenta.

3) Competência é a faculdade de mobilizar redes de atores em volta das mesmas situações, de compartilhar desafios, de assumir áreas de responsabilidade.

No dizer de Wittorski (2004), a competência tem a ver com a ação do indivíduo, ou do coletivo, em uma dada situação. Ela é finalizada (e não abstrata), contextualizada, específica e contingente. Conclui, ao afirmar que a competência é um processo que gera o produto acabado, que é a performance $e^{1}$ (mensurável e, por vezes, medida/avaliada em razão da competência).

Dutra (2001) ressalta que a competência é assunto muito procurado entre os vários empresários espalhados pelo mundo, e quem a utilizar pode garantir um futuro melhor ao ambiente organizacional. $\mathrm{O}$ autor faz referência a Fleury (2000), quando afirma que competências é um saber agir responsável e reconhecido, que

\footnotetext{
1 Performance refere-se ao desempenho do trabalhador na conclusão de sua atividade em seu contexto de trabalho.
} 
implica mobilizar, integrar, transferir conhecimentos, recursos, habilidades, que agreguem valor econômico à organização e valor social ao indivíduo.

Entretanto o autor enfatiza que a competência é compreendida por alguns teóricos da administração como um conjunto de conhecimentos, habilidades e atitudes necessários para que a pessoa desenvolva suas atribuições e responsabilidades. Ocorre que, para ele, o fato de as pessoas possuírem conhecimentos, habilidades e atitudes, não significa necessariamente benefício para a empresa, a menos que ocorra a entrega por parte dos funcionários, ou seja, que eles coloquem efetivamente em prática essa competência quando da ação laboral.

Nesse sentido, Ribeiro (2009) afirma que os estudiosos dos processos organizativos do trabalho têm produzido duas visões acerca das competências. A primeira, geralmente determinada pelos estudiosos franceses, coloca maior ênfase nas relações sociais, ou seja, o foco seria na ação relacionada à capacidade de influenciar outrem, mobilizar e aplicar recursos em dado contexto, agregando, por conseguinte, um valor ao indivíduo e ao contexto dos processos organizativos. A segunda se encontra nos estudos norte-americanos, em que possui ênfase destacada nas ações e nos resultados, a pressuposição de que as competências estariam diretamente relacionadas à capacidade de alcançar resultados superiores.

Carbone, Brandão, Leite e Vilhena (2006) fizeram uma conexão entre as duas correntes citadas anteriormente e definiram competência como não somente um conjunto de conhecimentos, habilidades e atitudes necessárias para exercer determinada função ou posto de trabalho, mas também como desempenho expresso pela pessoa em determinado contexto, em termos de comportamentos e realizações decorrentes da mobilização e aplicação de conhecimentos, habilidades e atitudes no trabalho.

Observação esta que fala de ou sobre competência, não é algo tão simples, como dá a entender uma corrente de autores da área de gestão de pessoas. Como vimos, não há unanimidade quanto à definição de competência. Isto quer dizer que o termo é utilizado com diversos sentidos e em diferentes contextos. No entanto existe um ponto em comum em todas as colocações referentes à questão das habilidades humanas, pois, quando aplicadas e reconhecidas em organizações de trabalho, tendem a gerar ganhos significativos tanto para o indivíduo, quanto para a empresa.
Desse modo, a noção de competência aparece quase sempre associada a expressões como: saber agir, mobilizar recursos, integrar saberes múltiplos e complexos, saber aprender, saber engajar-se, assumir responsabilidades, ter visão estratégica, entre outras. As competências devem agregar valor econômico para a organização e valor social, para o indivíduo (Fleury, 2000).

Com isso, a partir dessa concepção de competências, o trabalho não é mais o conjunto de tarefas associadas descritivamente ao cargo, mas se torna um prolongamento direto da competência que o indivíduo mobiliza em face de uma situação profissional.

As várias mudanças ocorridas nas empresas, nos últimos anos (globalização, reestruturação produtiva, aumento da competitividade, necessidade da utilização de técnicas avançadas de negociação, dentre outras), trouxeram com elas a necessidade do trabalho em equipe e, consequentemente, a valorização das competências individuais, só que trabalhando em coletivo (Carvalho, 2008; Dutra, 2001; Faissal, 2005).

\section{A seleção por competência}

Dentre as atividades desenvolvidas no modelo de competência, destacam-se a atração e a seleção de pessoas. Sabe-se que o discurso da competência vem se difundindo dia após dia nos espaços das organizações de trabalho. Apesar dessa propagação, especialmente no processo de atração e seleção de pessoas para o trabalho, não observamos relatos precisos na literatura científica que trata desse assunto, tão pouco experiências a respeito de como vem sendo feita e/ou como é avaliada esta modalidade de seleção. Presume-se que essa "nova" modalidade diminui as chances de a seleção não ser bem sucedida, visto que ela (seleção por competência) torna-se capaz de medir cada habilidade que os indivíduos possuem para um bom desempenho no posto de trabalho ou na profissão.

No modelo tradicional de seleção de pessoal, recorre-se, com frequência, à descrição e análise de cargos, na qual o selecionador tem acesso ao perfil do cargo ou função para a qual se fará o processo seletivo. Quando esse processo passa a ser operado pelo modelo da competência, entra em jogo novas exigências para inserção dos candidatos ao trabalho, implicando competências móveis, fluidas, que escapam ao tradicional perfil profissiográfico. 
Para atrair competências, selecioná-las adequadamente e gerar resultados esperados, é imprescindível que determinadas ações sejam estrategicamente planejadas, eticamente praticadas e que estejam alinhadas com a missão da organização (como já dito). Faissal, Passos, Mendonça e Almeida (2005) acreditam que o resultado da aplicação das técnicas de seleção por competência oferece as competências necessárias para as organizações de trabalho manterem-se competitivas.

Nesse contexto, pergunta-se: mas como se operacionaliza esse modelo de seleção por competências? Inicialmente, gostaríamos de atentar para os novos usos demarcados a esse tipo de seleção. Antes de falarmos em que consiste esse processo de seleção, faz-se necessário conhecer o modo de mapeamento das competências dos cargos e funções das organizações de trabalho.

Para que a seleção por competência seja bem sucedida, ela deve estar atrelada a um mapeamento das competências organizacionais. Nesse mapeamento, identifica-se o gap, ou lacuna, existente entre as competências necessárias ao alcance do desempenho esperado, e as competências já disponíveis na organização (Carbone et al., 2006, p. 52); ou seja, busca-se identificar a discrepância entre as competências necessárias para concretizar a estratégia corporativa e as competências internas existentes na organização (Ienaga, 1998 citada por Brandão \& Barhy, 2005).

Esse processo inicia-se com a identificação das competências (organizacionais e profissionais) necessárias à consecução dos objetivos da organização. Essa identificação começa, geralmente, com uma pesquisa documental, em que se inclui a análise do conteúdo da missão, da visão de futuro, dos objetivos, além de outros documentos relativos à estratégia organizacional (Carbone et al., 2006), diferenciando-se da descrição e análise de cargos tradicionais.

Essa pesquisa documental assemelha-se, e muito, à pesquisa bibliográfica. A diferença essencial entre ambas está na natureza das fontes. Enquanto a pesquisa documental vale-se de materiais que não recebem um tratamento analítico, ou que já tenham sidos recebidos de alguma forma, ainda assim podem ser re-elaborados de acordo com os objetos da pesquisa, a exemplo de gravações, memorandos, regulamentos, ofícios, boletins, relatórios de pesquisa, relatórios de empresas, tabelas estatísticas etc.. A pesquisa bibliográfica, por sua vez, procura a resolução de um problema (hipótese) por meio de referenciais teóricos publicados, analisando e discutindo as várias contribuições científicas a exemplo de livros e artigos científicos (Santos, 2008).

Outra técnica bastante utilizada no mapeamento das competências é a entrevista. Essa, geralmente, possibilita fazer a comparação da percepção dos entrevistados com os dados apurados na análise documental, visando a identificação das competências relevantes à organização (Brandão \& Barhy, 2005). A aplicação dessa técnica pressupõe um roteiro de perguntas, previamente elaborado pelo entrevistador, sobre interesses do candidato ao cargo, função ou em uma proposta de trabalho eventual. É destacado o grau de conhecimento do candidato em relação à organização na qual almeja trabalhar (Carbone et al., 2006).

Nessa direção, os autores citados anteriormente admitem o uso de outros métodos, (como e.g.) observação e questionários estruturados. A observação compõe-se de uma análise detalhada do objeto estudado, ou seja, das competências relevantes ao trabalho das pessoas. Uma de suas vantagens se dá pela possibilidade de se verificar detalhes do desempenho de pessoas e grupos, que muitas vezes podem ser omitidos por entrevistas ou questionários. Evidencia-se também que esse tipo de técnica não pode ser desenvolvido em um processo de seleção externa, uma vez que os trabalhadores, no momento da seleção, não pertencem ao quadro funcional da organização solicitante.

Considerado o instrumento mais utilizado no mapeamento de competências, o questionário estruturado possui a vantagem de facilitar a coleta de informações e análise dos dados. No entanto, para sua aplicação, é exigida, em princípio, uma aplicação prévia de uma ou mais técnicas já discutidas (pesquisa documental, entrevista ou observação), cujo objetivo é identificar os elementos para compor os itens do questionário.

Depois de identificados os ingredientes do trabalho, o passo seguinte consiste em definir a escala mais adequada para que os respondentes do questionário avaliem o grau de importância das competências. Porém, independentemente da escala de avaliação utilizada, é fundamental realizar uma validação semântica do questionário, antes de sua aplicação. Então, realizados os eventuais ajustes ou correções no instrumento de pesquisa, o pesquisador pode, finalmente, aplicá-lo junto a uma amostra maior, que seja representativa da população pesquisada (Brandão \& Barhy, 2005; Carbone et al., 2006). 
Além da identificação das competências necessárias à estratégia organizacional, o mapeamento de competências pressupõe também inventariar as competências internas já disponíveis na organização, com o propósito de identificar a lacuna entre as competências necessárias e as já existentes na organização. Tal procedimento, segundo aqueles autores, geralmente é realizado pela avaliação do desempenho, na qual resulta o chamado "diagnóstico de competências". Portanto, ao ser identificada a necessidade de aprendizagem pleiteada pelo trabalhador, a partir do diagnóstico, torna-se possível minimizar ou mesmo suprimir essa lacuna de competências.

Esse processo de mapeamento, que resulta na definição do perfil de competências da empresa, é imprescindível à seleção por competência, pois, sem esse instrumento, não teríamos como diferenciar esse tipo de seleção de pessoas de outros. Entretanto, Carvalho (2008) ressalta que essa construção do perfil pode ser o diferencial da seleção por competências. Para o autor, todo processo seletivo, mesmo no modelo mais tradicional de gestão de pessoas, precisará construir um perfil de competências, que é mais conhecido no modelo tradicional como "descrição e análise de cargos". De posse desse perfil, os profissionais poderiam se aproximar das competências necessárias para cada cargo.

Porém, ao analisar as descrições de cargos ao longo dos anos 1990, Dutra (2001) observou um quadro de mudanças expressivas. Para o autor, até o final dos anos 1980, as tradicionais descrições de cargos detinham-se exclusivamente às funções e tarefas a serem exercidas pelos trabalhadores no posto de trabalho. Já nos anos 2000, uma outra preocupação pode ser percebida, a saber: a de traduzir as expectativas de entrega/compromisso desses cargos, levando-se em consideração uma escala crescente de complexidade, o que desperta, mesmo que de modo intuitivo, certo interesse das empresas em relação às mudanças cunhadas no mercado, especialmente no âmbito da economia.

Por fim, o autor faz um alerta aos profissionais responsáveis por esse processo, agora redimensionado, de descrição e análise de cargos, no sentido de considerar as mudanças ocorridas no mundo do trabalho. A partir desse ponto de vista, a descrição facilitaria o conhecimento das competências internas, e também proporcionaria uma aproximação menos fictícia de captação de competências em seleção externa.

Dessa forma, o mapeamento de competências deve ser construído a partir do fortalecimento da parceria selecionador x requisitante do cargo ou função. A confecção desse perfil (não tradicional) visa a aproximar os requisitos e competências definidas a cada cargo, desde que se relacione às competências mapeadas.

\section{Considerações finais}

Propomos, nessa pesquisa descritiva-exploratória, de cunho bibliográfico, analisar o tema seleção por competência. Nesse sentido, no decorrer desse trabalho, foi possível mostrar que a noção de competência não é um modismo, tampouco poderíamos dizer que substitui a noção de qualificação, ou a esta se contrapõe.

Trata-se de uma transformação em longo prazo que, acompanhadas das mudanças ocorridas no mundo do trabalho, ocasionaram inúmeras exigências - agilidade, inovação, criatividade, efetividade de resultados aos trabalhadores e ao modo de selecioná-los.

No decorrer do estudo, foram encontradas dificuldades quanto a encontrar bibliografias precisas sobre o tema em questão (seleção por competência). Diante disso, sugerem-se novas investigações que relacionem o uso dessas técnicas com a efetividade dos resultados.

Nota-se também que, nos estudos encontrados, não há unanimidade quanto à definição de competência. Isso quer dizer que o termo é utilizado com diversos sentidos e em diferentes contextos. Diante disso, verificamos duas concepções de modelos de competências entre estudiosos e profissionais que versam sobre este tema.

De um lado, encontra-se um grupo vinculado à área de gestão de pessoas que defendem o modelo de seleção por competências por meio do antigo trinômio, outrora utilizado na clássica administração de recursos humanos (ARH), de avaliação de conhecimentos, habilidades e atitudes (CHA) como requisitos fundamentais que credenciam um profissional a exercer uma determinada função ou cargo. De outro, uma corrente de pensadores que caracterizam a competência como um retorno do trabalho ao trabalhador, como uma nova qualificação. Nessa segunda concepção, destacam-se os conceitos de entrega, responsabilidade, iniciativa e autonomia.

Conclui-se, portanto, que mesmo sendo enfatizadas algumas noções de seleção nesse estudo, não será possível destacar um modelo geral para esse "novo" tipo de seleção, embora se apresente uma perspectiva de mapeamento de competências que 
leva em conta interesse do trabalhador com a missão estratégica da organização.

\section{Referências}

Andrade, K. M. (2009). Práticas de recrutamento e seleção nas empresas. Recuperado em 14 jul. 2009, em http://www.iesb.br/psicologiaiesb/jan_2009/01_ psicologiaiesb_andrade_2009_1.htm

Brandão, H.P., \& Barhy, C. P. (2005). Gestão por competências: Métodos e técnicas para mapeamento de competências. RSP - Revista de Serviço Público, 56(2), 179-194.

Carbone, P. P., Brandão, H. P., Leite, J. B. D., \& Vilhena, R. M. P. (2006). Gestão por competência e gestão por conhecimento. Rio de Janeiro: FGV.

Carvalho, I. M. V., Passos, A. E. M., \& Saraiva, S. B. C. (2008). Recrutamento e seleção por competência. Rio de Janeiro: FGV.

Chiavenato, I. (1999). Gestão de pessoas: 0 novo papel dos recursos humanos nas organizações. Rio de Janeiro: Câmpus.

Clot, Y. (2010). A psicologia do trabalho na França e a perspectiva da clínica da atividade. Fractal: Revista de Psicologia, 22(1), 207-234.

Davel, E., \& Vergara, S. C. (2001). Gestão com pessoas e subjetividade. São Paulo: Atlas.

Dutra, J. S. (2001). Gestão por competências: Um modelo avançado para o gerenciamento de pessoas (5. ed.). São Paulo: Gente.

Faissal, R., Passos, A. E. M., Mendonça, M. C. F., \& Almeida, W. M. C. (2005). Atração e seleção de pessoas. Rio de Janeiro: FGV.

Ferreira, B. H. (2004). Novo Dicionário Aurélio da Língua Portuguesa. Curitiba: Positivo.

Fleury, M. T. (2000). Em busca da competência. Recuperado em 31 set. 2009, em http://www.anpad.org.br/ eneo/2000/dwn/eneo2000-24.pdf

Gramigna, M. R. (2007). Modelo de competências e gestão dos talentos (2. ed.). São Paulo: Pearson Prentice Hall.

Helal, D. H., \& Rocha, M. (2008). Da qualificação às competências: 0 que há de novo? E-CIVITAS - Revista Científica do Departamento de Ciências Jurídicas, Políticas e Gerenciais. Recuperado em 9 out. 2009, em http://site1.unibh.br/imgMarketing/revistas/dcjpg/ include/getdoc.php?id=87\&article $=17 \&$ mode $=$ pdf
Malvezzi, S. (2004). Prefácio. In A. V. B. Bastos, J. E. Borges-Andrade \& J. C. Zanelli (Ed.). Psicologia, organizações e trabalho no Brasil (pp. 13-18). Porto Alegre: Artmed.

Marras, J. P. (2000). Administração de recursos humanos: Do operacional ao estratégico (3. ed.). São Paulo: Futura.

Ministério da Defesa. (2006). Serviço militar: Histórico República Federativa do Brasil. Recuperado em 27 ago. 2009, em https://www.defesa.gov.br/servico_ militar/index.php?page=historico_servico_militar

Oliveira, E. F. (2008). Recrutamento e seleção. Griffon Serviços e Associados LTDA - Estudo no Departamento de Captura. Recuperado em 19 set. 2009, em http:// www.administradores.com.br/producao_academica/ recrutamento_e_selecao_griffon_servicos_e_associados_ltda_estudo_no_departamento_de_captura/1768/ download/

Ribeiro, M. A. (2009). Psicologia e gestão de pessoas: Reflexões críticas e temas afins (ética, competência e carreira). São Paulo: Vetor.

Roche, J. (2004). A dialética qualificação - competência: Estado da questão. In A. Tomasi (Ed.). Da qualificação à competência: Pensando o século XXI (pp. 33-50). Campinas: Papirus.

Sampaio, J. R. (1998). Psicologia do trabalho em três faces. In I. B. Goulart \& J. R. Sampaio (Ed.). Psicologia do trabalho e gestão de recursos humanos: Estudos contemporâneos (pp. 19-40). São Paulo: Casa do Psicólogo.

Santos, C. J. G. (2008). Tipos de pesquisa. Recuperado em 13 nov. 2009, em http://www.oficinadapesquisa. com.br/_OF.TIPOS_PESQUISA.pdf

Santos, O. B. (1985). Psicologia aplicada a orientação e seleção de pessoal. São Paulo: Pioneira.

Soares, C. (2007). Seleção por competência na prática de gestão de pessoas nas organizações. Recuperado em 13 maio 2009, em http://inf.unisul.br/ psicologia/ wp-content/uploads/2008/03/CarolinaSoares.pdf

Tomasi, A. (2004). Da qualificação à competência: Pensando o século XXI. Campinas: Papirus.

Zarifian, P. (2001). Objetivo competência: Por uma nova lógica. São Paulo: Atlas.

Zarifian, P. (2003). 0 modelo da competência: Trajetória histórica, desafios atuais e propostas. São Paulo: Senac.

Wittorski, R. (2004). Da fabricação das competências. In A. Tomasi (Ed.). Da qualificação à competência: Pensando o século XXI (pp. 75-90). São Paulo: Papirus. 